\section{Two Newly Observed Cases of Fish-eating in Anubis Baboons}

\author{
Akiko Matsumoto-Oda ${ }^{1,}$, , Anthony D. Collins ${ }^{2}$ \\ ${ }^{1}$ Graduate School of Tourism Sciences, University of the Ryukyus, \\ Okinawa 903-0213, Japan \\ ${ }^{2}$ The Jane Goodall Institute, Gombe Stream Research Centre, Kigoma P.O. \\ Box 185, Tanzania \\ "Author for correspondence (a_matsu@tm.u-ryukyu.ac.jp)
}

Most non-human primates are omnivorous and eat a wide variety of food types like as fruit, leaves, seeds, insects, gums or a mixture of these items. In spite of frequent eating of fish in human, there are few species to eat fishes in non-human primates. Observations of fish-eating in wild primates bring us an important cue for the question why humans have evolved appetite for fish. Here we report two new fish-eating cases observed in anubis baboons (Papio anubis) at the Mpala Research Centre, Kenya and the Gombe National Park, Tanzania. Both cases were observed in dry seasons, and two adult males and a young female ate recently dead or dying fish in each case. In these two cases, the opportunity of fish-eating occurred by chance and it will be difficult for them to eat fishes ordinarily.

\section{Keywords}

Papio anubis, dead fish, seasonality, opportunism, propagation

\section{Introduction}

In humans, fish accounted for $16.7 \%$ of the global population's intake of animal protein in 2010 (FAO, 2014). Observations of fish-eating behavior in non-human primates are, however, reported only on 10 species (Russon, Compost, Kuncoro, \& Ferisa, 2014): Horsfield's (Bornean) tarsier (Tarsius bancanus), Philippine tarsier (Tarsius syrichta), tufted capuchin (Cebus apella), Allen's swamp monkey (Allenopithecus nigroviridis), long-tailed macaque (Macaca fascicularis), Japanese macaque (Macaca fuscata), olive baboon (Papio anubis), chacma baboon (Papio ursinus), bonobo (Pan paniscus), and Bornean orangutan (Pongo pygmaeus). It brings a question why human often eat fishes whereas non-human primates rarely eat. Some non-human primates prey on other vertebrate, but they do not rely on meat as a major diet (Chapman, Rothman, \& Lambert, 2012). In general, body size and diet are related: the smallest primates $<1 \mathrm{~kg}$ are insectivore, middle size are frugivore and the largest size are folivore (Kay, 1984; Fleagle, 1999). This depends on that larger animals need more calories than small animals. Leaves are calories-less and folivore needs longer feeding time. The risk of losing time when folivore fail to catch fish or vertebrate might be serious for them. Examination of possible factors of fish-eating in non-human primates shed a light on this question.

One of the factors is seasonality. Catching fish becomes easier during the dry season because temporary small pools or shallow rivers appear (Hamilton \& Tilson, 1985; de Waal, 2001). Most of cases that non-human primates obtained fishes were beside shallow water (Stewart, Gordon, Wich, Schroor, \& Meijaard, 2008). In rehabilitant orangutans in Central Kalimantan, 79\% events $(19 / 24)$ were in the wet-dry transition or in the dry season, and they obtained $21 \%$ (4/19) of fish from shallow ponds and 79\% (15/19) on riverbanks (Russon et al., 2014). Hunting frequency becomes high when low availability of preferred foods create a need for fallback foods (e.g., Teleki, 1973; Rose, 2001). Indeed, non-human primates eat fish when there are fewer terrestrial plants (de Waal, 2001; Wrangham, Chenry, Seyfarth, \& Sarmiento, 2009; Stewart, 2010). When the artificial supply of food was decreased, male Japanese macaques in Koushima Island began to eat dead fish (Watanabe, 1989). From data on baboons inhabiting the Okavango Delta in Botswana, it is assumed that the use of aquatic underground storage organs provided fallback food in early hominins (Wrangham, 2005; Wrangham et al., 2009). In addition, early hominins possibly began to consume fish as a by-product of eating aquatic plants or aquatic invertebrates (Stewart, 2010; Russon et al., 2014).

Another factor is opportunity and propagation of fish-eating. Omnivores have contradictory behaviors for foods (omnivore' dilemma): searching for new food items to vary their diet (food neophilia) (e.g., Barnett, 1958; Milton, 1993) and fearing novel items that may be poisonous (food neophobia) (e.g., Weiskrantz \& Cowey, 1963; Visalberghi \& Fragaszy, 1995). Long-term observation is necessary to determine propagation speed and pattern of consumption of a novel food within an animal group. In Japanese macaques, Watanabe (1989) reported that fish-eating spread to $75 \%$ of the group members within 7 years. Leca, Gunst, Watanabe, and Huffman (2007) reported that more males ate fish than females, and that the dominant individuals spent more time feeding on fish than the subordinate ones. Moreover, fish-eating behavior was well maintained in terms of matrilineage. This suggests that dominance rank and matrilineage affect the diffusion of this behavior.

Here we report two new fish-eating cases observed in wild anubis baboons and consider what kind of situation fish eating rise in. Baboons have the largest bodies among living primates inhabiting the transitional zone between forests and savannas, and their body size is similar to that of early hominids. In the baboon genus, fish-eating has been reported in anubis and chacma baboons. Anubis baboons at the Gombe National Park, Tanzania, were 
observed eating the leftovers of dried small fish, dagaa, dried under the sun and left by fishermen (Goodall, 1971; Ransom, 1981). Fish-eating was more common in chacma baboons in Namibia, which ate both dead and live fish (Hamilton \& Tilson, 1985). The first case of our new reports was observed at Mpala, Kenya, where a baboon ate a fish at a seasonal pool. The second case was observed at Gombe where baboons ate a cichlid, Kuhe (Boulengerochromis microlepis).

\section{Methods}

The Mpala Research Centre on the Laikipia Plateau, Kenya is located to the northwest of Mt. Kenya, where the study of baboons commenced in August 2011 (Matsumoto-Oda, 2015). In September 2011, the size of AI group was at least 62 individuals that included 10 adult males and estimate 21 adult females.

The Gombe National Park, Tanzania, is located facing Lake Tanganyika. Study of anubis baboons at Gombe has been performed since 1967 (Packer, Tatar, \& Collins, 1998). In the early years of research on the baboons, fishermen dried small fish, Stolothrissa tanganicae (local name is dagaa) of about $7 \mathrm{~cm}$ size (Campbell, Verburg, Dixson, $\&$ Hecky, 2008), on the beach on the shores of the lake. Baboons were observed picking up the leftovers (Ransom, 1981; Goodall, 1971). However, the catching of fish by local people was prohibited by the national park authorities in 1998 (Pusey, Wilson, \& Collins, 2008), and since then, baboons have had no access to fish made available through human activities. In September 2008, the BA group was composed of a total of 38 individuals that included 10 adult males and 13 adult females.

\section{Results}

\section{Case I, Mpala}

13 September, 2011 (early dry season)

06:13 The observation of the AI group was started from the top of the cliff where was their sleeping site.

08:20 The group descended the cliff. The group spread out and some individuals stopped at a pool that is naturally dammed in the dry season. The distance in a straight line from the top of the cliff to the pool was $81 \mathrm{~m}$, and the difference in height was $16 \mathrm{~m}$. We observed the pool from the top of the cliff using $8 \times 8$ binoculars.

08:22 A young female that had arrived at the pool jumped into the water and returned to the bank with an approximately $20 \mathrm{~cm}$ size fish in its mouth. When the female left the water, the fish appeared to be dead. The female bit into the fish several times and threw away the leftover part (which we were unable to clearly identify).

Case II, Gombe (dry season)

11 September, 2008 (dry season)

07:36 The observations of the BA group was started at the lakefront.

11:27 An adult male, AZT (12-years-old, second-ranking) was sitting at the lakefront watching the lake (Fig. 1a). Two immature baboons were sitting close to him, but did not notice the object that $A Z T$ was looking at. Within $10 \mathrm{~m}$ from $A Z R$, an adult male $R E D$ (unknown age, fifth-ranking) groomed an estrous female, $M K A$ (15-years-old).

11:29 A recently dead or dying Kuhe floated in the water towards the shore. AZT stood up and watched the fish (Fig. 1b). He entered the water and swam towards the fish, and the two immature baboons followed him. AZT returned to the shore, holding the tail of the fish in his mouth (Fig. 1c). The Kuhe was approximately $40 \mathrm{~cm}$ in length. $A Z T$, standing at the shore, bit into the lower part of the head of the fish (Fig. 1d).

11:30 AZT sat down and held the part of the fish that he had bitten (Fig. 1e). He began to eat from the neck of the fish topped down (Fig. 1f).

11:31 The two immature baboons watched $A Z T$ from a distance of $1.5 \mathrm{~m}$ (Fig. $1 \mathrm{~g}$ ). $A Z T$ ate the fish along its back (Fig. 1h).

11:44 AZT ate the body of the fish first, and put the uneaten part of the head and tail by his left foot (Fig. 1i). STI (15-years-old, sixth-ranking) approached to a distance of $2 \mathrm{~m}$ and looked at $A Z T$.

11:48 $\quad M K A$ and $R E D$ passed nearby $A Z T$. Moreover, an estrous female $A J A$ (13-years-old) approached to $A Z T$, and they left together. $S T I$ went over to where $A Z T$ had been sitting and ate the remainder of the fish.

\section{1:51 STI left.}

\section{Discussion}

In Case I and II, anubis baboons ate fish in early dry or dry season. According to the study by Barton and Whiten (1993) that baboon foods were more numerous in the rainy season than in the dry season in nearby Mpala, Case I was observed during a period of scarce food. Previous studies on orangutans and Japanese macaques also reported that fish-eating occurred when fruits or foods were scarce (Watanabe, 1989; Russon et al., 2014). Our observation supports a hypothesis that fish-eating is favored as a fallback food when fruits or foods were scarce.

The baboons seemed to find fish by chance that were dying or had recently died and subsequently ate them in both of the cases. It suggests that fish-eating may occur by chance. It is completely different from orangutans that took fishes from nets of fishery (Russon et al., 2014) because it may show orangutans intend to obtain fishes. There is a possibility that a particular individual or group of baboon already has previous experience to eat fish and fish-eating behavior had spread as a culture. Unfortunately, we have no data on previous experience of the target individual eating fish. Moreover, detailed analyses on baboons' reaction to the fishes were difficult because of insufficient condition of field observations. We can say something, however, from indirect evidences. For Case I, Kuhe is a sought-after fish by people living near the lake. Although the sense of taste of non-human primates is not the same as that of modern humans, it might be similar (e.g., Steiner, Glaser, Hawilo, \& Berridge, 2001). When non-human primates bite into fish, it should remain in their memory as an attractive food if it has a good taste. However, Kuhe which is the biggest Cichlid species in Lake Tanganyika, 
a)

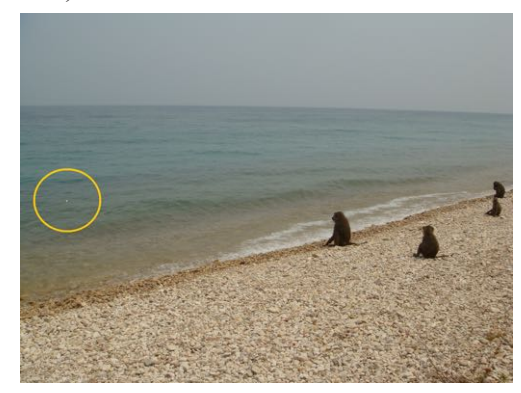

d)

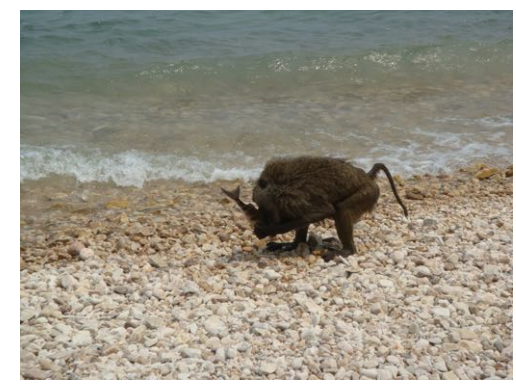

b)

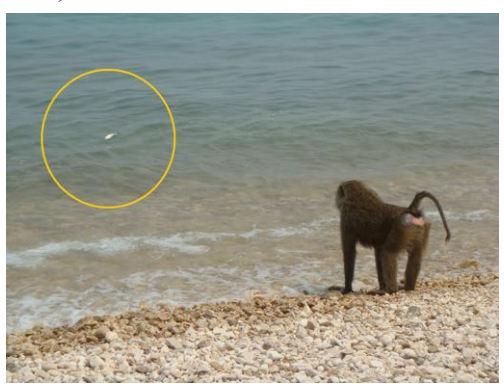

e)

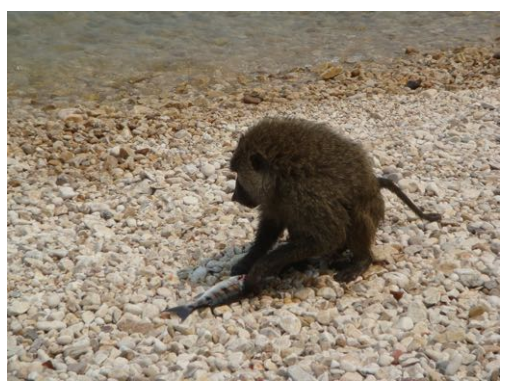

c)

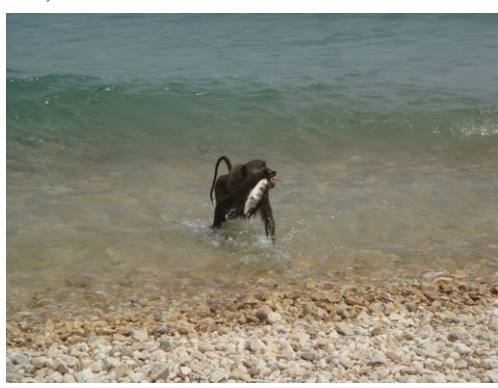

f)

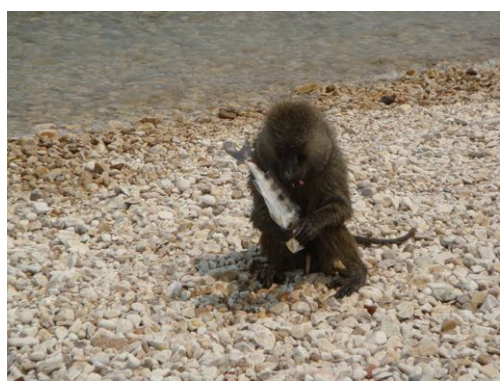

g)

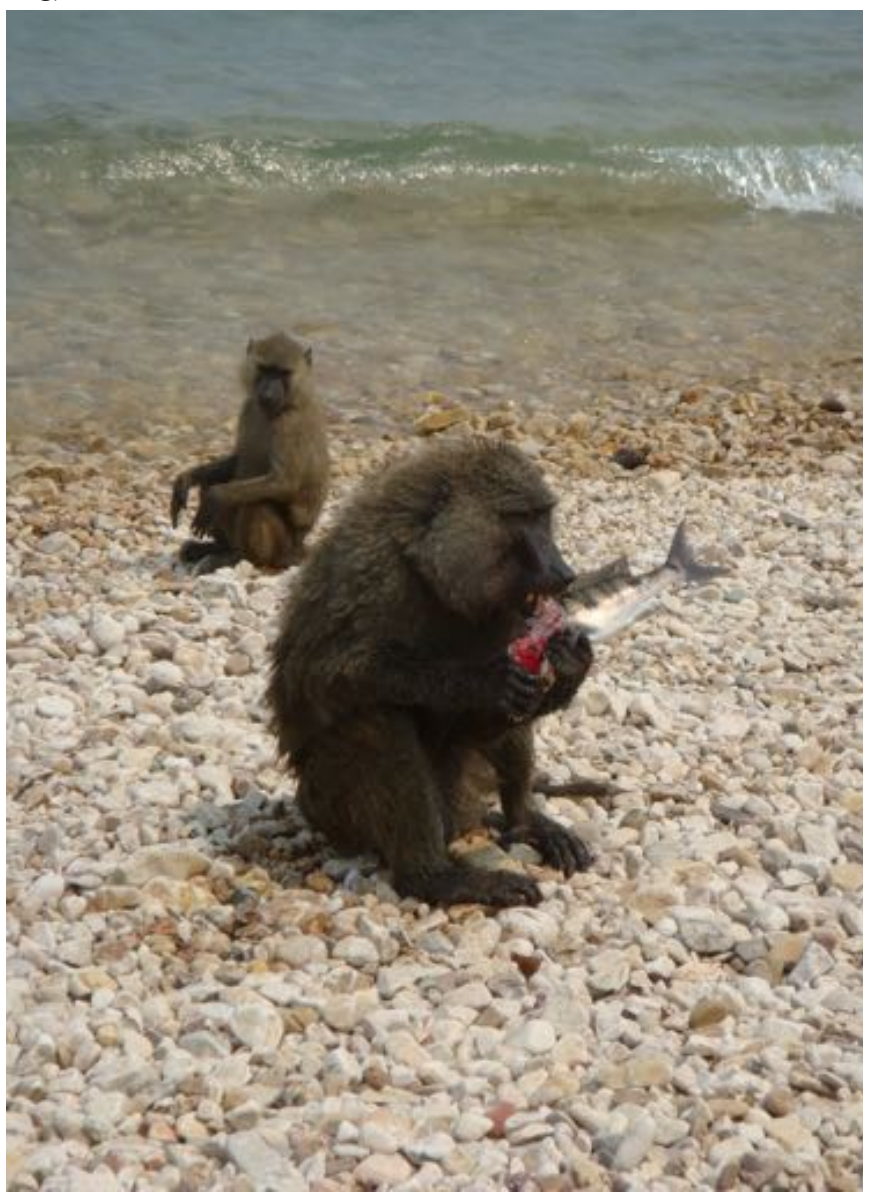

h)

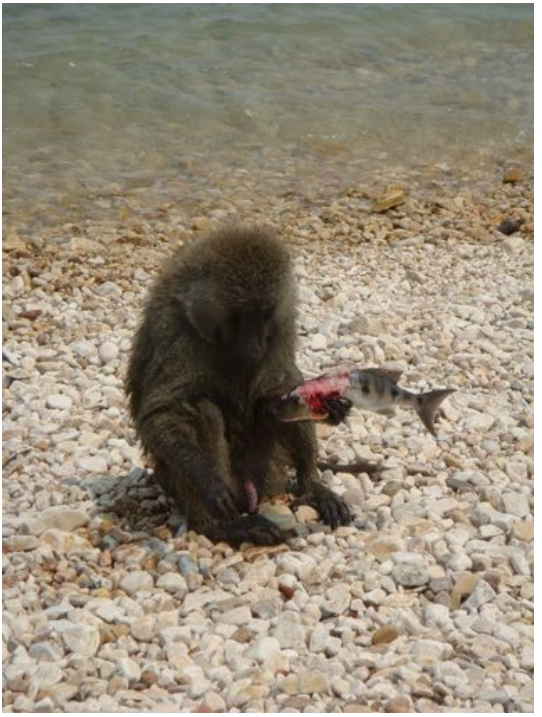

i)

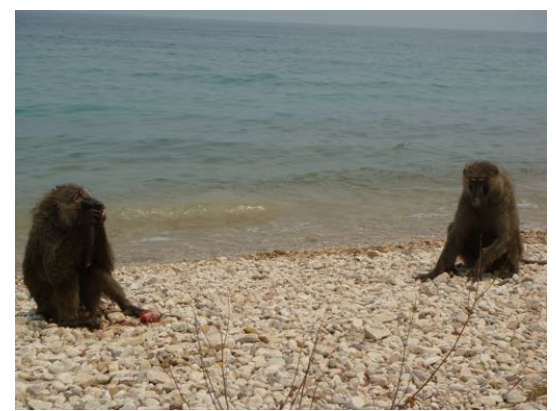

Figure 1. Fish-eating by an anubis baboon in Gombe National Park. a) b) A newly died or dying fish of endemic species in the Lake Tanganika, Kuhe (Boulengerochromis microlepis) floated out from offshore. c) An adult male baboon swam and brought the Kuhe. d) e) f) g) h) i) He ate it except entrails, backbone and cranial bone. 
inhabit water depths of 3-15 m (Bayona, 1991). Therefore, baboons cannot easily obtain Kuhe as food. When baboons walk along the lakefront, opportunities may present for them to obtain fish that float by chance towards the shore, such as observed in Case I. To be considered general food, however, opportunities for the animals to repeatedly eat certain novel foods are necessary (Takasaki 1983). To clarify the processes of adopted fish-eating or novel foods, further studies of non-human primates are required to update the lists of foods that they consume.

Finally let's be brought back to a question; why do humans often eat fish whereas non-human primates rarely do so? Unfortunately it seems to be difficult to date back to the evidences from ancient sites. Fish bones have been excavated from a Turkana Basin stratum dated at roughly 1.6 mya (Stewart \& Gifford-Gonzalez, 1994). Alternatively, fish bones were found at a site from the Middle Stone Age in South Africa, and most of the bones were inferred to be too larger to have been carried by seabirds (Henshilwood et al., 2001). Even if a fossil of fish is discovered, it is difficult to determine whether it provides evidence of human fish-eating. Stewart (2010) suggested that obtaining fish in early hominins was first inadvertent and then progressed successively to opportunistic hand-catching, deliberate hand-catching, and tool-catching. This pattern was almost reproduced in orangutan (Russon et al., 2014). If we follow this process, modern human fish-eating has been built on more advanced tool use. And, for this reason, modern human may be significantly outside the range of behaviors of other primates.

\section{Acknowledgement}

Local research supports and permissions were obtained from the Tanzania Commission for Science and Technology, Tanzania Wildlife Research Institute and Tanzania National Parks, Mpala Research Centre, National Commission for Science, Tecchnology and Innovation in Kenya and Kenya Wildlife Service. We thank Marini Bwenda, Sufi Rukamata (The Gombe baboon project team) and Andrea Surmat (The Mpala baboon project team) for their cooperation and assistance in field. We Thank to Drs. Anne E Pusey and Craig Packer for their advices. This research was partially supported by JSPS KAKENHI to A.M.O., Grant Nos. 19570230, 23405016, 26650172.

\section{References}

Barnett, S. A. (1958). Experiments on 'neophobia' in wild and laboratory rats. British Journal of Psychology, 49, 195-201. (doi: 10.1111/j.2044-8295.1958.tb00657.x)

Barton, R. A., \& Whiten, A. (1993). Feeding competition among female olive baboons, Papio anubis. Animal Behaviour, 46, 777-789. (doi: 10.1006/anbe.1993.1255)

Bayona, J. D. R. (1991). Some aspects of the biology of Kuhe, Boulengerochromis microlepis, in the Kigoma region, eastern coast of Lake Tanganyika. African Study Monographs 12, 63-74. (doi: 10.14989/68077)

Campbell, L., Verburg, P., Dixon, D. G., \& Hecky, R. E. (2008). Mercury biomagnification in the food web of Lake Tanganyika (Tanzania, East Africa). Science of the Total Environment, 402, 184-191. (doi: 10.1016/ j.scitotenv.2008.04.017)

Chapman, C. A., Rothman, J. M., \& Lambert, J. E. (2012).
Food as a selective force in primates. In J. C. Mitani, J. Call, P. M. Kappeler, R. A. Palombit \& J. B. Silk (Eds.), The evolution of primate societies (pp. 149168). Chicago: University of Chicago Press.

Fleagle, J. G. (1999). Primate adaptation and evolution. San Diego: Academic Press, Inc.

Food and Agricalture Organization of the United Nations, Fisheries Dept. (FAO). (2014). The state of world fisheries and aquaculture, 2014. Food \& Agriculture Org.

Goodall, J. (1971) In the shadow of man. New York: Houghton Mifflin.

Hamilton III, W. J. \& Tilson, R. L. (1985). Fishing baboons at desert waterholes. American Journal of Primatology, 8, 255-257. (doi: 10.1002/ ajp.1350080308)

Henshilwood, C. S., Sealy, J. C., Yates, R., CruzUribe, K., Goldberg, P., Grine, F. E., . . . Watts, I. (2001). Blombos Cave, southern Cape, South Africa: Preliminary report on the 1992-1999 excavations of the Middle Stone Age levels. Journal of Archaeological Science, 28, 421-448. (doi: 10.1006/ jasc.2000.0638)

Kay, R. F. (1984). On the use of anatomical features to infer foraging behavior in extinct primates. In P. S. Rodman \& J. G. H. Cant (Eds.), Adaptations for foraging in nonhuman primates (pp. 21-53). New York: Columbia University Press.

Leca, J. B., Gunst, N., Watanabe, K. \& Huffman, M. A. (2007). A new case of fish-eating in Japanese macaques: Implications for social constraints on the diffusion of feeding innovation. American Journal of Primatology, 69, 821-828. (doi: 10.1002/ajp.20401)

Matsumoto-Oda, A. (2015). How surviving baboons behaved after leopard predation: a case report. Anthropological Science, 123, 13-17. (doi: 10.1537/ ase.150223)

Milton, K. (1993). Diet and primate evolution. Scientific American, 269, 86-93. (doi: 10.1038/scientificamerican0606-22sp)

Packer, C., Tatar, M., \& Collins, A. (1998). Reproductive cessation in female mammals. Nature, 392, 807-811. (doi: 10.1038/33910)

Pusey, A. E., Wilson, M. L., \& Collins, D. A. (2008). Human impacts, disease risk, and population dynamics in the chimpanzees of Gombe National Park, Tanzania. American Journal of Primatology, 70, 738744. (doi: 10.1002/ajp.20567)

Ransom, T. W. (1981). Beach troop of the Gombe. Lewisburg: Bucknell University Press.

Rose, L. M. (2001). Meat and the early human diet. In C. B. Stanford \& H. T. Bunn (Eds.), Meat-eating and human evolution. (pp. 141-159). Oxford: Oxford University Press.

Russon, A. E., Compost, A., Kuncoro, P., \& Ferisa, A. (2014). Orangutan fish eating, primate aquatic fauna eating, and their implications for the origins of ancestral hominin fish eating. Journal of Human Evolution, 77, 50-63. (doi: 10.1016/j.jhevol.2014.06.007)

Steiner, J. E., Glaser, D., Hawilo, M. E., \& Berridge, K. C. (2001). Comparative expression of hedonic impact: Affective reactions to taste by human infants and other primates. Neuroscience \& Biobehavioral Reviews, 25, 53-74. (doi: 10.1016/S0149-7634(00)00051-8)

Stewart, A. M. E., Gordon, C. H., Wich, S. A., Schroor, P., \& Meijaard, E. (2008). Fishing in Macaca fascicularis: A rarely observed innovative behavior. International Journal of Primatology, 29, 543-548. (doi: 10.1007/ 
s10764-007-9176-y)

Stewart, K. M., \& Gifford-Gonzalez, D. (1994). An ethnoarchaeological contribution to identifying hominid fish processing sites. Journal of Archaeological Science, 21, 237-248. (doi: 10.1006/jasc.1994.1024)

Stewart, K. M. (2010). The case for exploitation of wetlands environments and foods by pre-sapiens hominins. In S. C. Cunnane \& K. M. Stewart (Eds.), Human brain evolution: The influence of freshwater and marine resources (pp. 137-171). New York: John Wiley and Sons.

Takasaki, H. (1983). Mahale chimpanzees taste mangoes toward acquisition of a new food item? Primates, 24, 273-275. (doi: 10.1007/BF02381089)

Teleki, G. (1973). The predatory behavior of wild chimpanzees. Lewisburg, PA: Bucknell University Pres.

Visalberghi, E. \& Fragaszy, D. (1995). The behaviour of capuchin monkeys, Cebus apella, with novel foods: The role of social context. Animal Behaviour, 49, 1089-1095. (doi: 10.1006/anbe.1995.0137)

de Waal, F. B. M. (2001). The ape and the sushi master: Cultural reflections of a primatologist. London: Penguin Books.

Watanabe, K. (1989). Fish: A new addition to the diet of Japanese macaques on Koshima Island. Folia Primatologica, 52, 124-131. (doi: 10.1159/000156391)

Wrangham, R. (2005). The delta hypothesis: Hominoid ecology and hominin origins. In D. E. Lieberman, R. J. Smith \& J. Kelley (Eds.), Interpreting the past: Essays on human, primate and mammal evolution in honor of David Pilbeam (pp. 231-242). Boston, Brill Academic.

Wrangham, R. W., Cheney, D., Seyfarth, R., \& Sarmiento, E. (2009). Shallow-water habitats as sources of fallback foods for hominins. American Journal of Physical Anthropology, 140, 630-642. (doi: 10.1002/ ajpa.21122)

Weiskrantz, L. \& Cowey, A. (1963). Striate cortex lesions and visual acuity of the rhesus monkey. Journal of Comparative and Physiological Psychology, 56, 225231. (doi: $10.1037 / \mathrm{h} 0043778$ ) 